US Army Corps

of Engineers $s_{\circledast}$

Engineer Research and

Development Center

\title{
Preliminary Measurements on the Geography of Urban VHF Radio-Frequency Noise
}

Caitlin E. Haedrich, Daniel J. Breton, D. Keith Wilson

August 2020 
The U.S. Army Engineer Research and Development Center (ERDC) solves the nation's toughest engineering and environmental challenges. ERDC develops innovative solutions in civil and military engineering, geospatial sciences, water resources, and environmental sciences for the Army, the Department of Defense, civilian agencies, and our nation's public good. Find out more at www.erdc.usace.army.mil.

To search for other technical reports published by ERDC, visit the ERDC online library at https://erdclibrary.on.worldcat.org/discovery. 


\section{Preliminary Measurements on the Geography of Urban VHF Radio-Frequency Noise}

Caitlin E. Haedrich, Daniel J. Breton, D. Keith Wilson

Cold Regions Research and Engineering Laboratory

U.S. Army Engineer Research and Development Center

72 Lyme Road

Hanover, NH 03712

Final report

Approved for public release; distribution is unlimited.

Prepared for U.S. Army Corps of Engineers

Washington, DC 20314

Under Program Element 0611102T, Project Number T442, and Task Number 01 


\section{Preface}

This study was conducted for the U.S. Army Corps of Engineers under Program Element 0611102T, Project T442, and Task Number 01. The Technical monitor was Dr. Marino A. Niccolai.

The work was performed by the Signature Physics Branch of the Research and Engineering Division, U.S. Army Engineer Research and Development Center, Cold Regions Research and Engineering Laboratory (ERDCCRREL). At the time of publication, Mr. Dr. Marino A. Niccolai was Branch Chief; Mr. James Horne was Division Chief; and Dr. Robert Davis was the Technical Director for Geospatial Research and Engineering. The Deputy Director of ERDC-CRREL was Mr. David B. Ringelberg, and the Director was Dr. Joseph L. Corriveau.

This paper was originally published in proceedings of the Military Sensing Symposium 2018, held October 22 - 25, 2018 in Gaithersburg, MD. Funding was provided by the US Army Basic Research Program.

The Commander of ERDC was COL Teresa A. Schlosser and the Director was Dr. David W. Pittman. 


\title{
Preliminary measurements on the geography of urban VHF radio-frequency noise
}

\begin{abstract}
Radio-frequency (RF) noise has typically been measured at a handful of fixed, representative locations within the urban environment (Achatz, Lo, Papazian, Dalke, \& Hufford, 1998; Achatz \& Dalke, 2001; Dalke, Achatz, Lo, Papazian, \& Hufford, 1997; Wepman \& Sanders, 2011; Wagstaff \& Merricks, 2005; Spaulding \& Disney, 1974). In this work, we discuss the development of a mobile RF noise measurement system and the necessary geospatial and statistical post-processing techniques required to characterize the variations in noise on the street-scale in the VHF sections $(60-300 \mathrm{MHz})$ of the spectrum. We discuss the design of our mobile noise measurement system, with special focus on the choice and calibration of preselection filters and preamplifiers necessary to reliably measure low RF noise levels while avoiding intermodulation distortion problems that arise in an environment with many strong emitters. Additionally, we describe post-processing techniques developed to reliably merge and interpolate the RF data with geolocation data which are collected on two very different (microsecond and multisecond, respectively) timescales. We use a preliminary urban dataset from Boston, MA to show that the geo-statistical properties of RF noise power can vary appreciably over street-scale distances, and that these spatial variations are repeatable over tactically relevant times.
\end{abstract}




\subsection{Introduction}

Radio-frequency (RF) background noise is a spatially-varying and critical parameter for predicting radio communication and electromagnetic sensor system performance in urban environments. High levels of RF noise can degrade RF system performance by decreasing intelligibility, increasing bit-error rates, and decreasing sensitivity in analog voice, digital, and sensing systems respectively. Therefore, accurate measurements of noise power and its variability throughout the urban environment are necessary to support military and first responder operations.

RF noise comes from many different sources, both man-made and natural. Natural noise such as galactic and atmospheric sources are most powerful in the HF and VHF ranges (ITU, 2013). At frequencies typically used for line-of-sight communications by military and first responders in the high VHF to UHF, natural noise is low in power (ITU, 2013), while above $30 \mathrm{MHz}$, man-made dominates natural noise even in rural settings (Leferink, et al., 2010).

Modern man-made RF noise consists of unintentional emissions from sources such as electronic devices, power transmission lines, and internal combustion engine ignitions (ITU, 2013). Electronic devices such as cellular phones, wireless internet routers and printers, in particular, are relevant to the urban noise environment because of their increasing pervasiveness in urban environments over the last decade.

Our early understanding of urban man made noise was developed in the 1970's. Spaulding and Disney (1974) conducted a large-scale survey of background noise including urban, rural and residential measurements taken in North America, Europe and Asia. Their study provided the foundational dataset for ITU Recommendation P.372 on Radio Noise (ITU, 2013), a widely-used model for predicting background RF noise. ITU-R P.372 assumes noise power centered at a given frequency between 0.3 to $250 \mathrm{MHz}$ has a Gaussian distribution when expressed in decibels, a model first presented by Hagn and Sailors (1979). Hagn and Sailors (1979) also discuss a simple model for noise power variance based on frequency.

Since the 1970's, substantial efforts have been made to update and expand the surveys of Spaulding and Disney (1974). Achatz and Dalke (2001) conducted a noise power survey in the Denver and Boulder areas of Colorado in the $137 \mathrm{MHz}$ and $402.5 \mathrm{MHz}$. Wagstaff and Merricks (2005) conducted a similar study to Disney and Spalding (1974) across the UK. Most recently, Wepman and Sanders (2011) conducted measurements around the greater Denver area at $112.5 \mathrm{MHz}, 221.5 \mathrm{MHz}$ and $401 \mathrm{MHz}$. Achatz and Dalke (2001), Wagstaff and Merricks (2005), and Wepman and Sanders (2011) each constructed noise measurement facilities housed in vans that were dispatched to different stationary or fixed sites where they collected noise measurements. Wagstaff and Merrick's (2005) results, in particular, indicate that the background RF noise may have changed significantly since Disney and Spalding (1974) study with changing electronic device technology and usage. None of these studies characterized spatial variation in noise power.

To address the lack of spatial discrimination in previous work, we developed and deployed a mobile, calibrated and tunable (30 to $300 \mathrm{MHz}$ ) RF noise measurement system, utilizing GPS to locate measurements in space. Our measurement system is designed to measure the modern urban noise field by characterizing spatial variability of urban RF noise. This paper provides an overview of the mobile measurement system and presents preliminary results collected in Boston, MA. 


\subsection{Methods}

\subsection{Noise Measurement Theory}

The relationship between a transmitted signal and the measured signal at the receiver can be summarized by a link budget (Norton, 1956). In this section, we follow the common practice of using capital letter to denote variables in decibels and their lower case partners for the corresponding linear value.

$$
P_{0}+L_{t}+G_{t}=P_{r}-P_{n}+L_{b}\left(d_{0}\right)+G_{r}+L_{r}+F_{n}+B+10 \log _{10}(k T)
$$

where

$P_{0}$ is the transmission power of the signal $(\mathrm{dBm})$

$L_{t}$ is the insertion losses of the transmitting system components such as cables $(\mathrm{dB})$

$G_{t}$ is the transmitting antenna gain (dBi)

$P_{r}$ is the received signal power $(\mathrm{dBm})$

$P_{n}$ is the received noise power, both internal and external $(\mathrm{dBm})$

$L_{b}\left(d_{0}\right)$ is the transmission loss over range $d_{0}(\mathrm{~dB})$

$G_{r}$ is the receiving antenna gain $(\mathrm{dBi})$

$L_{r}$ is the insertion loss of the receiving system components $(\mathrm{dB})$

$F_{n}$ is the total noise figure of system measured in $\mathrm{dB}$ relative to thermal noise $(\mathrm{kTb})$

$B$ is the receiver noise bandwidth $(\mathrm{dB})$

$k$ is Boltzmann's constant, $1.38 \times 10^{\wedge-23} \mathrm{~J} \mathrm{~K}^{-1}$

$T$ is the receiver temperature, typically assumed to be $290 \mathrm{~K}(62.33 \mathrm{~F})$

Because there is no known signal transmitted when measuring noise, we ignore the left hand side $\left(P_{0}, L_{t}\right.$ and $G_{t}$ ) because they all concern transmitted signal power. We also remove $L_{b}\left(d_{0}\right)$ and $L_{r}$ (path loss and insertion loss, respectively) which also apply to transmitted signal power. For the purpose of this discussion, we assume the receiving antenna is isotropic so the antenna gain $\left(G_{r}\right)$ is 0 . Since our transmitted signal is powerless, we ignore $P_{r}$. Thus, the measured noise power is:

$$
P_{n}=F_{n}+B+10 \log _{10}(k T)
$$

Moving from decibels to linear units, this equation becomes:

$$
p_{n}=f_{n} k T b
$$

The total noise factor, $f_{n}$, can be further broken down into internal and external factors (Achatz \& Dalke, 2001) where internal factors result from receiving system noise only.

$$
f_{n}=f_{a}+l_{c} l_{t} f_{r}-1
$$

where

$f_{n}$ is the noise factor

$f_{a}$ is the received external noise factor where $f_{a}=\frac{p_{a}}{k T b}$ and $p_{a}$ is the total external received noise power

$l_{c}$ is the loss factor for the receiving antenna circuit 
$l_{t}$ is the loss factor of the transmission cable connecting the antenna and receiver

$f_{r}$ is the receiver system internal noise factor

We are interested in $f_{a}$, the total external noise power received by the antenna. Solving for $f_{a}$ yields:

$$
f_{a}=f_{n}-l_{c} l_{t} f_{r}+1
$$

If we further assume the antenna circuit and cables are lossless, we can simplify (5) to:

$$
f_{a}=f_{n}-f_{r}+1
$$

Substituting (3) into equation (6), we relate total measured noise power $\left(p_{n}\right)$ to receiving antenna external noise factor $\left(f_{a}\right)$.

$$
f_{a}=\frac{p_{n}}{k T b}-f_{r}+1
$$

The receiver system internal noise factor, $f_{r}$, can be found experimentally with proper equipment, is unique to each system, and must be determined in order to accurately report values of $f_{a}$.

\subsection{System Hardware Characteristics}

The measurement system, shown schematically in Figure 1 with system specifications listed in Table 1, is controlled using a ruggedized laptop computer with a solid state drive to allow for fast writing speeds. The laptop simultaneously records data collected by a GPS unit and the spectrum analyzer. The spectrum analyzer is has the capability to function as an RF recorder and is set to record in-phase and quadrature (IQ) data in a $1 \mathrm{MHz}$ bandwidth. A limiter protects the spectrum analyzer front end from signals powerful enough to cause damage.

A bank of tunable bandpass filters is used for preselection. Like most spectrum analyzers,

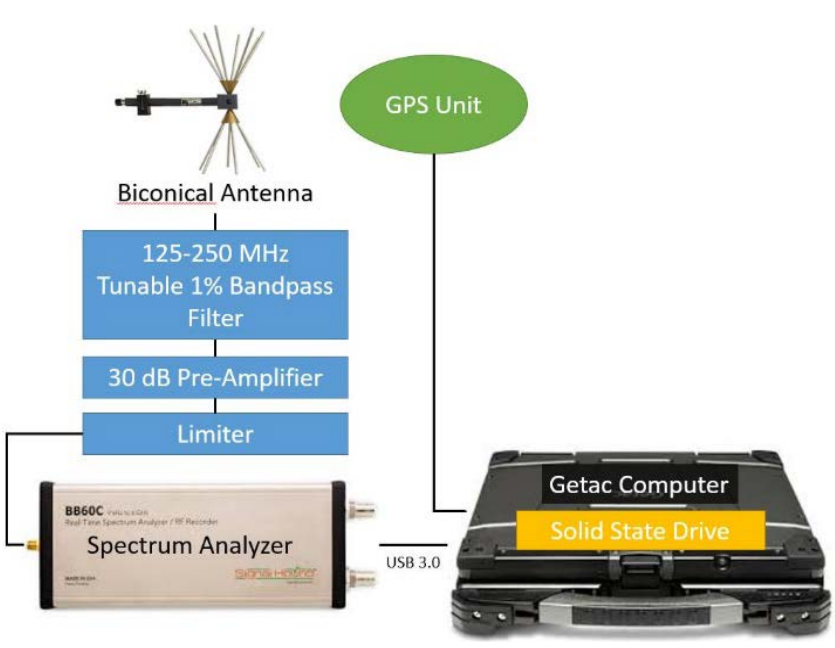

Figure 1. Diagram of Mobile Noise Measurement System. the Signal Hound BB60C has no internal pre-selection filtering capability, implying that all radiofrequency power collected by the antenna (including very strong emitters and low-level noise) reaches the $\mathrm{RF}$ front end of the spectrum analyzer. Failing to use preselection filters to exclude intentional emitters often leads to significant overload of the spectrum analyzer front end, resulting in intermodulation distortion and other spurious signals contaminating the measured noise power. Although the noise figures of tunable filters are higher than static ones, we opt for tunable because they give more flexibility in the field where one may not know a priori which frequencies will be free of emitters. Switching between the filters is done manually, disconnecting the system and antenna and reconnecting to the desired filter.

The $30 \mathrm{~dB}$ pre-amplifier is critical to the system as it lowers the overall system noise figure to approximately the noise figure of the pre-amplifier, as discussed in Seybold (2005). The noise measurement system was housed in a hand-pulled cart with the antenna held at 2 meters above ground level on a fiberglass tripod (see Figure 3). The cart also carried a 7Ah 12V sealed lead-acid battery for the preamplifier, additional laptop batteries, maps, camera and other field supplies. The filters and 
preamplifier were placed on a foam layer in an effort to reduce vibrations from the rolling cart. Cable connections were also checked regularly for proper torque.

Table 1. System Specifications

\begin{tabular}{|l|l|}
\hline Device & Brand and Model \\
\hline GPS & GlobalSat BU-353S4 Cable GPS with USB interface \\
\hline Antenna & A.H. Systems, Inc. SAS-545 Biconical Antenna (30 MHz-1 GHz) \\
\hline Pre-Amplifier & A.H. Systems, Inc. PAM-0202 30dB Preamplifier \\
\hline Tunable 1\% Bandpass Filters & $\begin{array}{l}\text { K\&L Microwave 5BT-500/1000-1-N/N } \\
\text { K\&L Microwave 5BT-125/250-1-N/N }\end{array}$ \\
\hline Limiter & MiniCircuits VLM-63-2W-S+ \\
\hline Spectrum Analyzer & Signal Hound BB60C Spectrum Analyzer/RF Recorder \\
\hline Laptop Computer & Getac B300 G5 \\
\hline
\end{tabular}

\subsection{System Sensitivity and Calibration}

As shown in Equation (7), to measure the external noise power $\left(f_{a}\right)$, we need to determine the system's internal noise factor $\left(f_{r}\right)$. We use the Y-Factor method (also referred to as noise diode calibration) as described by Hess (1998) and Keysight Technologies (2018). Because of the time used to complete the YFactor method, the measurement was completed a laboratory setting. In the field, we check the system noise figure, $F_{r}$, using a 50-ohm terminator attached in place of the antenna to ensure that our equipment is properly set up and our system noise figure matches the lab measurements. Minimum detectable signal is the sum of thermal noise and the system noise figure. Maximum measurable power is taken from the Signal Hound BB60C user manual's typical performance values.

Table 2. System Noise Figures, gain and sensitivity.

\begin{tabular}{|l|l|l|l|l|l|}
\hline $\begin{array}{c}\text { Frequency } \\
(\mathrm{MHz})\end{array}$ & $\begin{array}{c}\text { Noise Figure } \\
(\mathrm{dB} \text { above } \\
\text { thermal noise })\end{array}$ & $\begin{array}{c}\text { Noise Figure } \\
\text { Uncertainty } \\
(\mathrm{dB})\end{array}$ & $\begin{array}{c}\text { Gain } \\
(\mathrm{dB})\end{array}$ & $\begin{array}{c}\text { Min. Detectable } \\
\text { Signal in } 1 \mathrm{MHz} \\
\text { bandwidth }(\mathrm{dBm})\end{array}$ & $\begin{array}{c}\text { Max. Measurable } \\
\text { Power } 1 \mathrm{MHz} \\
\text { bandwidth }(\mathrm{dBm})\end{array}$ \\
\hline 142 & 7.55 & \pm 0.0015 & 27.08 & -106.45 & -43.9 \\
\hline 246.5 & 6.64 & \pm 0.0015 & 27.95 & -107.36 & -44.8 \\
\hline
\end{tabular}

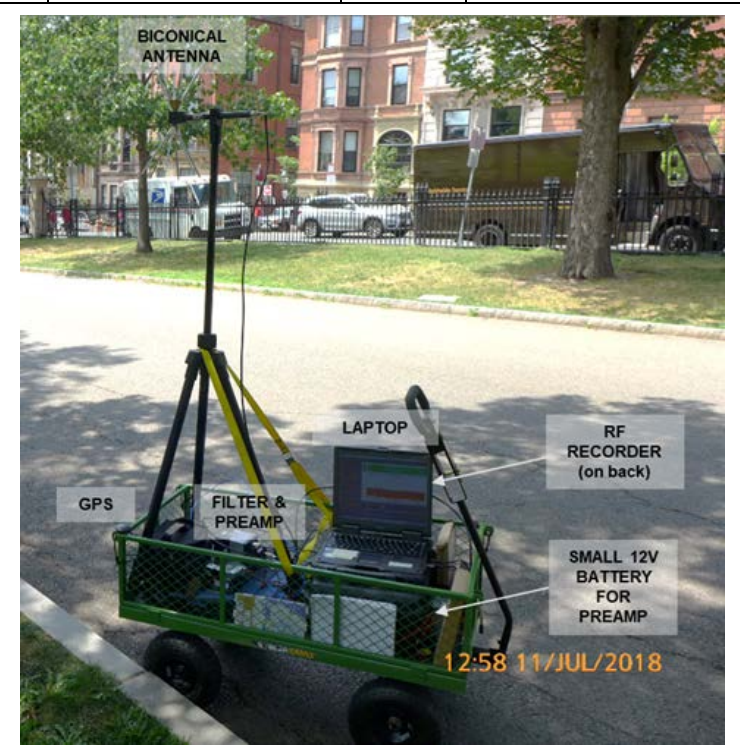

Figure 2. Noise Measurement System deployed in Boston, MA, USA. 


\subsection{Survey Location and Methods}

Boston, the study site, features dense high-rise buildings primarily used as office space and some as hotels and residences. Boston Common, a large park, is adjacent to the heart of downtown. A route (shown in Figure 3) was planned to intersect most of areas of the downtown. After surveying the spectrum from 125 to $250 \mathrm{MHz}$ for several minutes, 2 frequencies on federal exclusive portions of the

Table 3. Survey itinerary in Boston, MA on July, $13^{\text {th }}, 2018$.

\begin{tabular}{|l|l|}
\hline Time & Measurement \\
\hline $0800-0850$ & 1 Lap recording at $142 \mathrm{MHz}$ \\
\hline $0900-1040$ & 2 Laps recording at $246.5 \mathrm{MHz}$ \\
\hline $1055-1140$ & 1 Lap recording at $142 \mathrm{MHz}$ \\
\hline
\end{tabular}
spectrum (with no strong emitters immediately adjacent in frequency) were identified as appropriate for noise measurements. The route is approximately $2 \mathrm{~km}$ long and can be walked with the cart in less than an hour allowing for multiple laps at each frequency, enabling separation of spatial from temporal variability. The system measures one frequency at a time so measuring at several frequencies requires multiple laps. A summary of the system testing and data collection activities is shown in Table 3 .

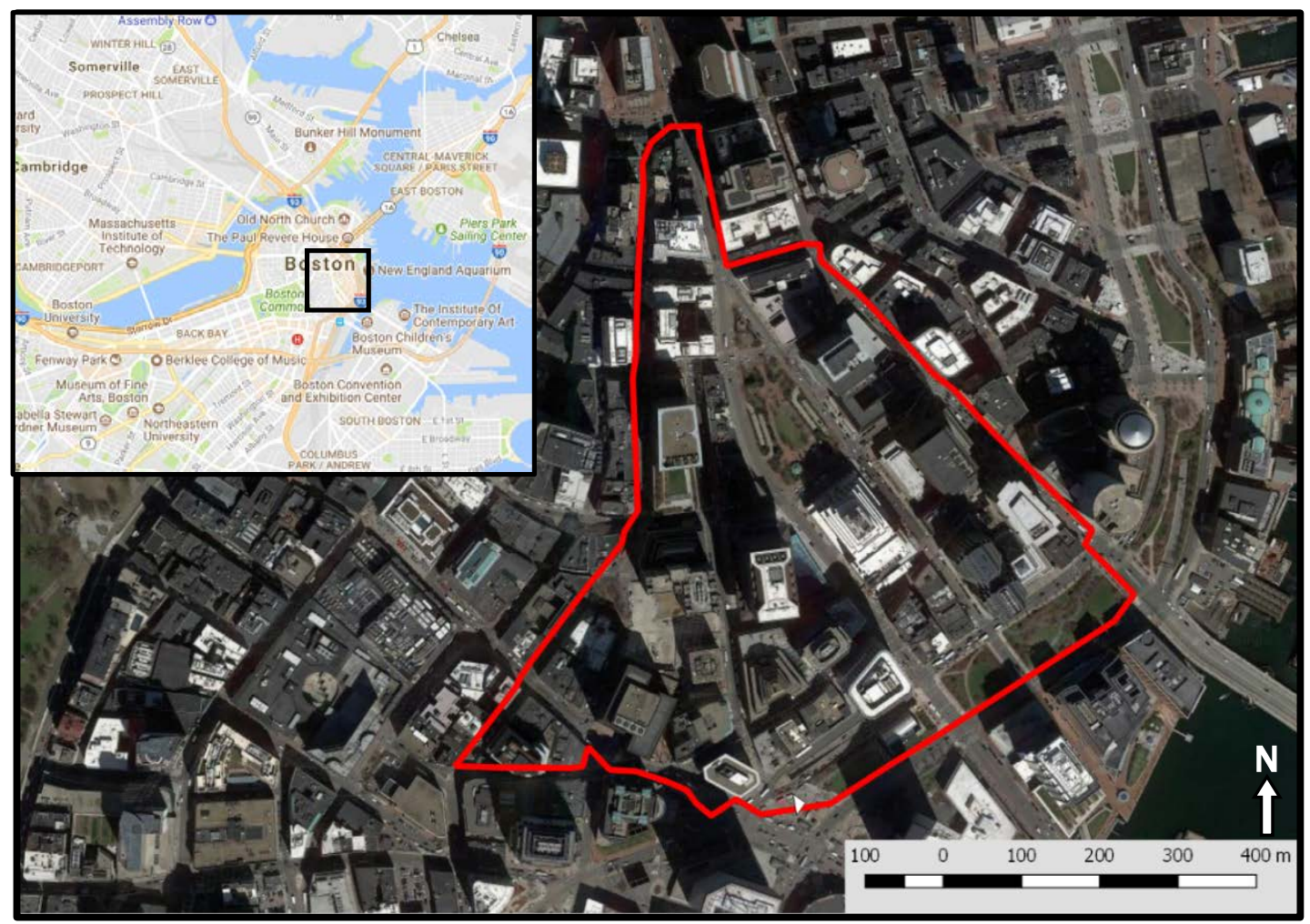

Figure 3. Map of survey area and route through downtown Boston, MA, USA from Base map from Google Satellite, accessed September 2018 and Google Maps (inset map) accessed August 2018.

\subsection{Methods of Analysis}

After returning to the lab, the binary IQ files and geolocation data are analyzed using a suite of Python scripts developed at our laboratory. The binary files are read and divided into 1-minute sections to avoid overloading the computer RAM. These 1-minute sections are merged with geolocation data by associating noise recorded within \pm 0.5 seconds of each GPS point's timestamp with the location. The median external noise power, $F_{a m}$, is calculated for the 1 -second noise sample at each GPS point. The GPS points along with their associated median external noise powers are then imported into QGIS as delimited text files to visualize variability. 


\subsection{Results}

Our preliminary survey results from Boston show a significant noise power variability on the blockscale at 142 and $246.5 \mathrm{MHz}$. For each frequency, the distribution of median noise powers $\left(F_{a m}\right)$ measured at each GPS point is shown in Figure 4.
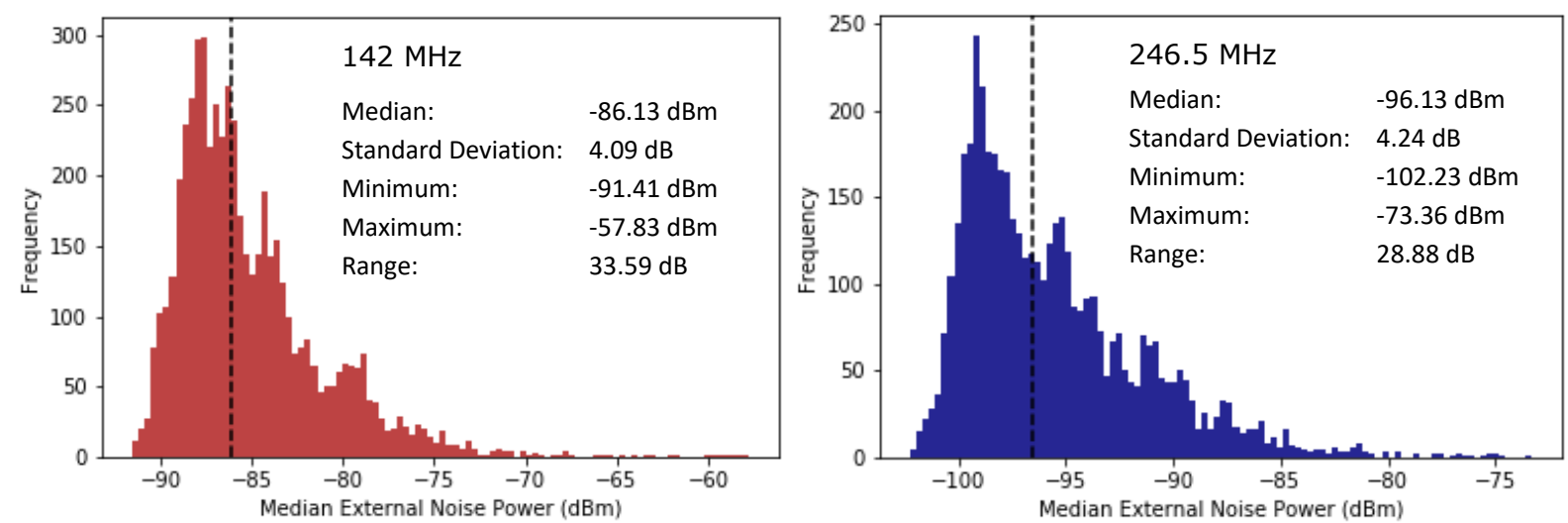

Figure 4. Histograms showing the distribution of median external noise power $\left(F_{a m}\right)$ measured at each GPS point for the $142 \mathrm{MHz}$ (left, red) and 246.5 MHz (right, blue) bands.

At both survey frequencies, the GPS experienced a significant amount of drift when deep in the urban canyon among high rise buildings, resulting in a path that wanders far from the actual route walked shown in Figure 3. In areas where the GPS completely lost reception, the points are interpolated along a straight line. The drift and interpolated points can make it difficult to determine where the high readings were located.

As shown in Figure 5 and Figure 6, even with GPS drift, we found high median noise powers clusters. In the $142 \mathrm{MHz}$ band, we found 3 of these hotspots spread along our route which were, on average, 566 meters apart. The maximum value, $-57.83 \mathrm{dBm}$, is found in the southwestern area of the route and is surrounded by high rise buildings housing several telecommunications and technology businesses, among other businesses and restaurants (Google Maps, 2018). The minimum median power, -91.41 $\mathrm{dBm}$, is on the Boston Greenway at the southern end the route, a relatively open area close to the river. The average cluster diameter is 165 meters and the minimum is 526 meters away from the maximum.

In the $246.5 \mathrm{MHz}$ band, the gradient between hotspots and low power areas was markedly steeper. We observed 5 hotspots with an average spacing of 218 meters. The maximum value was located in a similarly to the $142 \mathrm{MHz}$ maximum, in the southeastern area of the route among business and restaurants. Although the Greenway is similarly low powered as in the $142 \mathrm{MHz}$ band, the minimum is on the northern side the route. It is difficult to infer where along the route the exact location of minimum due to GPS drift and the top of the route has a mix of high and low power readings. The area at the top of the route is a mixed use area with several large skyscrapers containing businesses, hotels and restaurants. It is also at the heart of downtown and has several historical sites such as the Old State House, a small park and the Boston Massacre Site. The average cluster diameter is 117 meters and the minimum is 616 meters away from the maximum. 


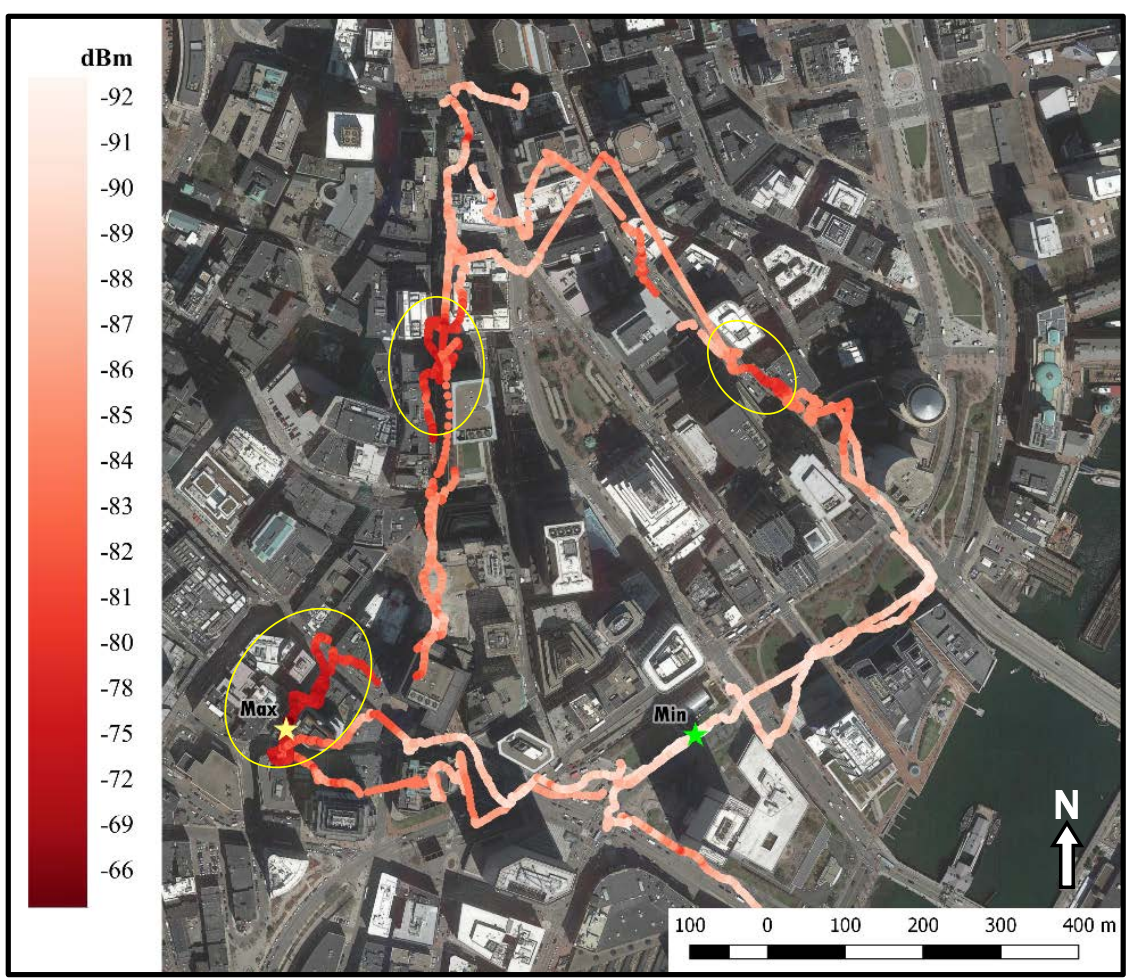

Figure 5. Map of Median Noise Power at $142 \mathrm{MHz}$ in downtown Boston, MA. Areas with clustered high measurements are circled in yellow. The minimum and maximum median noise powers are marked with stars. Base map from Google Satellite, accessed September 2018.

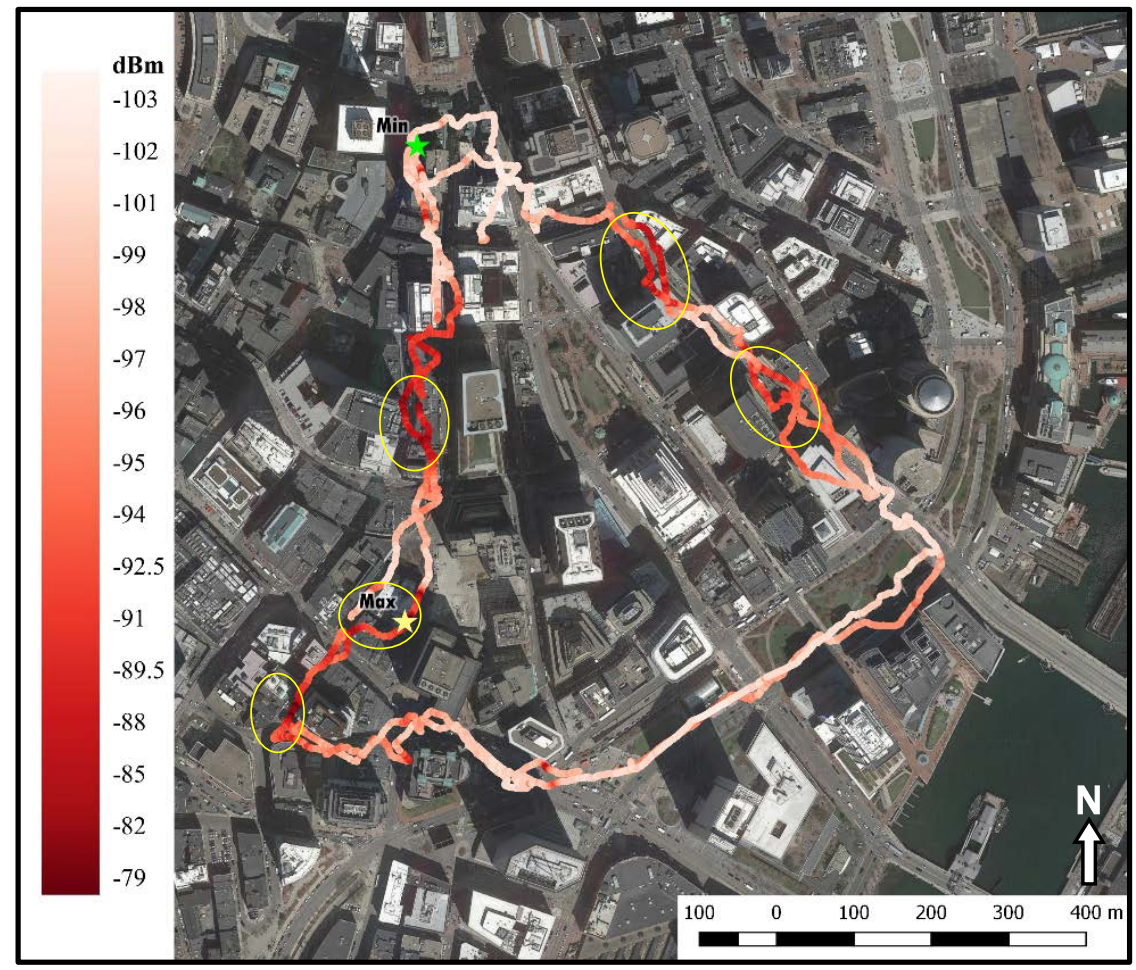

Figure 6. Map of Median Noise Power at 246.5 MHz in downtown Boston, MA. Areas with clustered high measurements are circled in yellow. The minimum and maximum median noise powers are marked with stars. Base map from Google Satellite, accessed September 2018. 


\subsection{Discussion}

Our results reveal substantial noise power spatial variability on the sub-block scale. The ITU Recommendation on Radio Noise (2013), briefly discusses variability of noise power between locations. They report upper and lower decile deviations of $8.4 \mathrm{~dB}$ in urban environments at frequencies between 0.3 and $250 \mathrm{MHz}$. While it is unclear what type or scale of location variability the report is referencing or how the report defines upper and lower deciles deviation, we find the difference between the first decile and the median to be 2.91 and $3.26 \mathrm{~dB}$ (lower decile deviation) and 6.72 and $6.89 \mathrm{~dB}$ between the last decile and the median (upper decile deviation) for $142 \mathrm{MHz}$ and $246.5 \mathrm{MHz}$, respectively. Contrary to the assumption of ITU-R P.372, the large difference between our lower and upper decile deviations shows our observed variation in median noise power $\left(F_{a m}\right)$ is not Gaussian (Figure 4 ) as assumed by the ITU's symmetrical, Gaussian variation of 8.4 dB. While other studies (Wagstaff \& Merricks, 2005; Wepman \& Sanders, 2011; Achatz \& Dalke, 2001) address temporal variations in median noise power $\left(F_{a m}\right)$ and variation in noise power $\left(F_{a}\right)$, spatial variation at the sub-city scale is unreported except for ITU's brief mention.

Our overall median noise power was higher at $142 \mathrm{MHz}$ than $246.5 \mathrm{MHz}$ but our noise measurements were also much higher than predicted by previous models and studies. The ITU (2013) model and Hagn and Sailors (1979) predict the noise power at $142 \mathrm{MHz}$ (median $-86.13 \mathrm{dBm}$ ) are significantly higher than the 246.5 MHz measurements $(-96.56 \mathrm{dBm})$; this is also corroborated by many other studies including Spaulding and Disney (1974), Achatz and Dalke (2001), Wagstaff and Merricks (2005) and Wepman and Sanders (2011). The ITU model also predicts the median external noise power in an urban environment will be $-96.77 \mathrm{dBm}$ in a $1 \mathrm{MHz}$ bandwidth at $142 \mathrm{MHz}$ and $-103.40 \mathrm{dBm}$ at $246.5 \mathrm{MHz}$. Our results were consistently 5 to $10 \mathrm{~dB}$ higher than the ITU model, indicating that the urban noise field may have evolved since the measurements of Spaulding and Disney (1974) and revisions of the ITU model (2013).

Tall buildings and the deep urban canyon caused problems for GPS reception and accuracy. In future work, a rolling survey wheel will keep track of distance walked and trigger 1 second IQ measurements every 1 meter. The rolling survey wheel will also mitigate sampling bias that results from using the GPS; as our walking speed inevitably varies while navigating the urban environment, the GPS point density varies (a point is recorded every second). Since our GPS point density varies, the noise power measurements have uneven spatial sampling. A rolling survey wheel will ensure samples are taken every meter instead of every second as the current GPS setup did.

The survey conducted in Boston offers a preliminary look at urban RF noise power variability and planned future work will expand and improve our current dataset. The noise measurement system presented in this paper can measure frequencies between 30 and $1000 \mathrm{MHz}$; planned future surveys will increase the number of frequencies measured to better capture frequency-dependent spatial noise power variability. Although multiple laps were conducted to begin to address temporal variation, the survey was conducted entirely during the morning on a normal work day; in future work, we plan to conduct measurements at different times of the day. Finally, by recording IQ data, we can expand our analysis to include characterization of impulsive noise.

\subsection{Acknowledgements}

The authors would like to thank Jeffery A. Wepman of the Institute of Telecommunications Sciences for his advice and guidance on best practices for measuring noise. This research would not have been possible without the administrative support of Claudia Grant and the support and guidance of Dr. Andrew Niccolai. Funding provided by the US Army Basic Research Program. Permission to publish granted by Director, Cold Regions Research and Engineering Laboratory. 


\subsection{References}

Achatz, R. J., \& Dalke, R. A. (2001). Man-Made Noise Power Measurements at VHF and UHF Frequencies. Tech. rep. 02-390, U.S. Dept. Commerce.

Achatz, R., Lo, Y., Papazian, P., Dalke, R., \& Hufford, G. (1998). Man-made noise in the 136 to 138-MHz VHF meteorological satellite band. Tech. rep. 98-355, National Telecommunications and Information Administration.

Dalke, R., Achatz, R., Lo, Y., Papazian, P., \& Hufford, G. (1997). Measurement and analysis of man-made noise in VHF and UHF bands. Wireless Communications Conference, 1997., Proceedings (pp. 229-233). IEEE.

Hagn, G. H., \& Sailors, D. B. (1979). Empirical Models for Probability Distributions of Shortterm Near Environmental Man-Made Radio Noise Levels. Record of the 3rd Symposium and Technical Exhibition on Electromagnetic Compatability, (p. 355).

Hess, G. C. (1998). Handbook of Land-Mobile Radio System Coverage. Artech House.

ITU. (2013). Radio Noise. Recommendation 372, International Telecommunications Union, Radiocommunications Sector, Geneva.

Keysight Technologies. (2018, June 29). Noise Figure Measurement Accuracy: The Y-Factor Method. Retrieved from Keysight Technologies Online: http://literature.cdn.keysight.com/litweb/pdf/5952-3706E.pdf

Leferink, F., Silva, F., Catrysse, J., Batterman, S., Beauvois, V., \& Roc'h, A. (2010). Man-Made Noise in Our Living Environments. Radio Science Bulletin, 334, 49-57.

Norton, K. A. (1956). Point-to-point radio relaying via the scatter mode of tropospheric propagation. IRE Transactions on Communications Systems, 4, 39-49.

Seybold, J. S. (2005). Introduction to RF propagation. John Wiley \& Sons.

Spaulding, A. D., \& Disney, R. T. (1974). Man-made radio noise, part 1: Estimates for business, residential, and rural areas. OT Report 74-38, U.S. Dept. Commerce, Office of Telecommunications.

Wagstaff, A., \& Merricks, N. (2005). Man-made noise measurement programme. IEE Proceedings - Communications, 152, 371-377.

Wepman, J. A., \& Sanders, G. A. (2011). Wideband Man-Made Radio Noise Measurements in the VHF and low UHF Bands. Tech. rep. 11-478, National Telecommunications and Information Administration. 


\section{REPORT DOCUMENTATION PAGE}

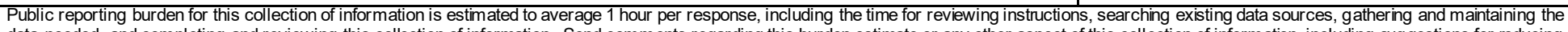

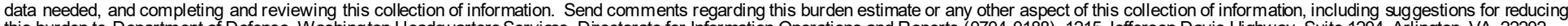

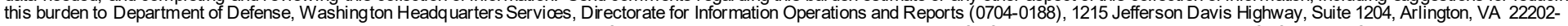

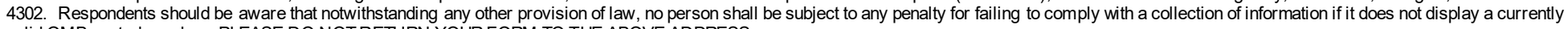
valid OMB control number. PLEASE DO NOT RETURN YOUR FORM TO THE ABOVE ADDRESS.
1. REPORT DATE
August 2020
2. REPORT TYPE
Final

4. TITLE AND SUBTITLE

3. DATES COVERED (From - To)

5a. CONTRACT NUMBER

Preliminary Measurements on the Geography of Urban VHF Radio-Frequency Noise

5b. GRANT NUMBER

5c. PROGRAM ELEMENT NUMBER

$0611102 \mathrm{~T}$

6. AUTHOR(S)

Caitlin E. Ha edrich, Da nielJ. Breton, D. Keith Wilson

5d. PROJECT NUMBER

T442

5e. TASK NUMBER

01

5f. WORK UNIT NUMBER

7. PERFORMING ORGANIZATION NAME(S) AND ADDRESS(ES)

U.S. Army Engineer Research and Development Center

8. PERFORMING ORGANIZATION REPORT NUMBER

Cold Regions Research and Engineering Laboratory

72 Lyme Road

ERDC/CRREL MP-20-13

Ha nover, NH 03755

9. SPONSORING / MONITORING AGENCY NAME(S) AND ADDRESS(ES)

10. SPONSOR/MONITOR'S ACRONYM(S)

U.S. Army Corps of Engineers

Washington, DC 20314-1000

USACE

11. SPONSOR/MONITOR'S REPORT NUMBER(S)

\section{DISTRIBUTION / AVAILABILITY STATEMENT}

Approved for public release; distribution is unlimited.

\section{SUPPLEMENTARY NOTES}

Origina lly published in proceedings of the Military Sensing Symposium 2019, held February $25-28,2019$ in Orla ndo, FL. Funding was provided by the US Army Basic Research Program.

\section{ABSTRACT}

Radio-frequency (RF) noise has typically been measured at a handful of fixed, representative locations within the urban environment (Achatz, Lo, Papazian, Da lke, \& Hufford, 1998; Achatz \& Dalke, 2001; Dalke, Achatz, Lo, Pa pazian, \& Hufford, 1997; Wepman \& Sanders, 2011; Wa gstaff \& Merricks, 2005; Spaulding \& Disney, 1974). In this work, we discuss the development of a mobile RF noise measurement system and the necessary geospatial and statistical post-processing techniques required to characterize the variations in noise on the street-scale in the VHF sections $(60-300 \mathrm{MHz})$ of the spectrum. We discuss the design of our mobile noise measurement system, with special focus on the choice and calibration of preselection filters and preamplifiers necessary to reliably mea sure low RF noise levels while a voiding intermodulation distortion problems that arise in an environment with many strong emitters. Additionally, we describe post-processing techniques developed to relia bly merge and interpolate the RF data with geolocation data which are collected on two very different (microsecond and mult isecond, respectively) timescales. We use a preliminary urban dataset from Boston, MA to show that the geo-statistical properties of RF noise power can vary a ppreciably over street-scale distances, and that these spatial variations are repeatable over ta ctically relevant times.

\section{SUBJECT TERMS}

Urban, Radio frequency, Ra dio measurements, Noise

\begin{tabular}{|c|c|c|c|c|c|}
\hline 16. SECURITY CL & IFICATION OF: & & 17. LIMITATION & 18. NUMBER & 19a. NAME OF RESPONSIBLE PERSON \\
\hline $\begin{array}{l}\text { a. REPORT } \\
\text { Uncla ssified }\end{array}$ & $\begin{array}{l}\text { b. ABSTRACT } \\
\text { Uncla ssified }\end{array}$ & $\begin{array}{l}\text { c. THIS PAGE } \\
\text { Unclassified }\end{array}$ & UU & 16 & $\begin{array}{l}\text { 19b. TELEPHONE NUMBER } \\
\text { (include area code) }\end{array}$ \\
\hline
\end{tabular}

